\title{
Psychological Predictors of Professional Burnout among Priests, Religious Brothers, and Religious Sisters in Italy: The Dark Triad versus the Bright Trinity?
}

\author{
Leslie J. Francis $^{1}$ (D) . Giuseppe Crea $^{2}$ (D)
}

Accepted: 29 March 2021 / Published online: 12 June 2021

(c) The Author(s) 2021

\begin{abstract}
Drawing on data provided by 287 Catholic priests, religious brothers, and religious sisters from different parts of Italy (130 men and 157 women), this study explored the effect of three dark psychological variables and three bright psychological variables on levels of professional burnout as assessed by the two scales of the Francis Burnout Inventory (emotional exhaustion and satisfaction in ministry). The three dark psychological variables assessed by the Short Dark Triad were Machiavellianism, subclinical narcissism, and subclinical psychopathy. The three bright psychological variables were purpose in life, emotional intelligence, and religious faith. After controlling for personal factors (age and sex) and personality factors (extraversion and emotionality), the data demonstrated that the three bright psychological factors (purpose in life, emotional intelligence, and religious faith) served as independent and cumulative predictors of higher levels of satisfaction in ministry and that the three dark psychological factors had no effect on satisfaction in ministry. Two of the three dark psychological factors (Machiavellianism, and subclinical psychopathy) served as independent and cumulative predictors of higher levels of emotional exhaustion in ministry, and purpose in life served as a predictor of lower levels of emotional exhaustion in ministry.
\end{abstract}

Keywords Catholic priests · Catholic sisters · Dark triad · Purpose in life $\cdot$ Emotional intelligence $\cdot$ Intrinsic orientation $\cdot$ Burnout

A growing body of empirical research has been concerned to assess levels of burnout experienced by clergy and religious professionals, using either the Maslach Burnout Inventory (Maslach \& Jackson, 1985) or the Francis Burnout Inventory (Francis et al., 2005). Studies using the Maslach Burnout Inventory (in its original form) have been reported by Warner and Carter (1984), Strümpfer and Bands (1996), Rodgerson and Piedmont (1998), Stanton-Rich and Iso-Ahola (1998), Virginia (1998), Evers and Tomic (2003), Golden et al. (2004), Raj and

Leslie J. Francis

leslie.francis@warwick.ac.uk

1 Centre for Educational Development, Appraisal and Research (CEDAR), The University of Warwick, CV4 7AL Coventry, UK

2 Pontifical Salesian University, Rome, Italy 
Dean (2005), Beebe (2007), Miner (2007a, 2007b), Doolittle (2007, 2010), Chandler (2009), Miner et al. (2009), Buys and Rothmann (2010), Joseph et al. (2010), Parker and Martin (2011), Joseph et al. (2011), Rossetti and Rhoades (2013), Küçüksüleymanoğlu (2013), Randall (2013), Herrera et al. (2014), Crea and Francis (2015), Büssing et al. (2017), Vicente-Galindo et al. (2017), Chan and Chen (2019), and Dias (2019).

Studies using the Francis Burnout Inventory among clergy have been reported by Francis et al. (2008b), Francis et al. (2009), Robbins and Francis (2010), Brewster et al. (2011), Francis et al. (2012), Robbins et al. (2012), Barnard and Curry (2012), Randall (2013), Francis et al. (2013a, b, c), Francis and Crea (2015), Francis et al. (2015, 2017b), Durkee-Lloyd (2016), Village et al. (2018), and Francis et al. (2019a).

As well as mapping the levels of burnout experienced by clergy and religious professionals, this growing body of literature has been concerned to identify and to map the predictor variables of individual difference in levels of experienced burnout (see Francis, 2018). In this context, four main categories of predictor variable have been documented: personal factors, personality factors, contextual factors, and psychological factors. The present study builds on and contributes to the body of research specifically concerned with the contribution of psychological factors to individual differences in levels of experienced burnout among clergy. In particular, the present study focuses first on the potential impact of the cluster of three dark psychological factors recently conceptualized as the 'dark triad.' Then, the study introduces the new concept of the 'bright trinity,' a cluster of three bright psychological factors already identified within the field of clergy studies.

\section{The dark triad}

The 'dark triad' of three offensive but nonpathological personality constructs is a term coined by Paulhus and Williams (2002) that became well established in the literature during the following decade (for a review, see Furnham et al., 2013). The burgeoning of more recent research has been stimulated by the emergence of sets of psychometric instruments that propose more economical assessment of these constructs, including the Short Dark Triad (SD3), comprising 27 items (Jones \& Paulhus, 2014), and the Dirty Dozen, comprising 12 items (Jonason \& Webster, 2010). The dark triad draws together the three constructs of Machiavellianism, subclinical narcissism, and subclinical psychopathy. These three constructs are intercorrelated to some extent but also clearly independent. To varying degrees, all three constructs entail a socially malevolent character with tendencies of self-promotion, emotional coldness, duplicity, and aggressiveness.

Machiavellianism characterized by manipulativeness, callous affect, and a strategic-calculating orientation, was shaped by Christie and Geis (1970), who drew on a selection of statements from Machiavelli's original books (see Machiavelli, 1981). The 20-item Mach-IV Inventory that they developed from these statements predicted individuals who were more likely to behave in a cold, manipulative fashion in laboratory and real-world studies.

Subclinical narcissism characterized by grandiosity, entitlement, dominance, and superiority, was shaped by Raskin and Hall's (1979) delineation of a subclinical version of the DSM-defined personality disorder. They developed the 40-item Narcissistic Personality Inventory (NPI) on large samples of students. Their notion of subclinical narcissism has been well supported by a strong research literature (Morf \& Rhodewalt, 2001a).

Subclinical psychopathy characterized by high impulsivity, high thrill-seeking, low empathy, and low anxiety, was shaped by Hare (1985) and Lilienfeld and Andrews (1996) among others. Hare 
(1985) developed the 31-item Self-Report Psychopathy Scale (SRP) from items that differentiated clinically diagnosed psychopaths from nonpsychopaths. This measure was subsequently validated in nonclinical samples by Forth et al. (1996).

In the development of the Short Dark Triad (SD3), Jones and Paulhus (2014) tried to shape and to sharpen the differentiation between the three constructs. Distinguishing Machiavellianism from subclinical psychopathy, Jones and Paulhus (2014) argued that Machiavellians plan ahead, build alliances, and do their best to maintain their positive reputation, whereas psychopaths behave impulsively, abandon friends and family, and give little heed to their reputation (Hare \& Neumann, 2008). Machiavellians tend to be strategic rather than impulsive (Jones \& Paulhus, 2011a), and they tend to avoid manipulating family members (Barber, 1998). Psychopaths tend to lie for immediate rewards, even if those lies compromise their long-term interest (Paulhus \& Jones, 2017). Their callous manipulation, combined with recklessness and thrill-seeking, tends to be reflected in bold and relentless pursuit of self-interest (Hare \& Newmann, 2008).

For their understanding of subclinical narcissism, Jones and Paulhus (2011b, 2014) drew on Kernberg (1975) and Kohut (1978). They argued that

narcissistic behaviour was marked by manipulation and callousness, much like Machiavellianism and psychopathy. Intraphysically, however, narcissism was defined by a clash between a grandiose identity and underlying insecurities. (Jones \& Paulhus, 2014, p. 29)

Narcissistic individuals are endlessly seeking ego-reinforcement (Morf \& Rhodewalt, 2001b) that can lead to self-destructive behaviors (Vazire \& Funder, 2006). Narcissistic grandiosity promotes a sense of entitlement (Bushman et al. 2003) that may result in aggression if that grandiosity is threatened (Bushman \& Baumeister, 1998; Jones \& Paulhus, 2010). Narcissism involves self-deception; narcissists' belief in their boastful claims tend to be maintained even when it can be verified that they exaggerate their competence (Paulhus \& Williams, 2002).

Drawing on this sharpened differentiation between Machiavellianism, subclinical narcissism, and subclinical psychopathy, Jones and Paulhus (2014) developed a pool of 41 items in which the Machiavellianism items comprised four themes (cynicism, coalition building, planning, and reputation), the subclinical narcissism items comprised four themes (entitlement, exhibitionism, grandiosity, and leadership), and the subclinical psychopathy items comprised four themes (antisocial behavior, callous affect, erratic lifestyle, and shortterm manipulation). Drawing on data provided by 489 adults, Jones and Paulhus (2014) employed exploratory factor analysis and exploratory structural equation modeling to identify three sets of nine items each that distinguished between the three constructs embraced by the dark triad.

\section{The bright trinity}

Within the broader field concerned with the science of clergy psychological well-being, attention has been drawn to three bright psychological factors that have been shown to have a positive effect on clergy well-being. These three factors, characterized in the present study as the 'bright trinity' in juxtaposition with the dark triad, are purpose in life, emotional intelligence, and intrinsic religiosity.

Purpose in life occupies a particularly interesting position within the range of constructs that measure and reflect distinctive aspects of personal well-being since purpose in life may be of particular relevance for engaging dialogue between positive psychology 
and empirical theology or pastoral sciences. From a theological perspective, following the pioneering work of Tillich (1952), purpose in life is understood to be central to the very essence of religion. Substantive analyses of religion point to the beliefs, teachings, and rituals that explicitly address the fundamental questions concerning meaning and purpose in life. From a psychological perspective, the notion of purpose in life has been brought into particular prominence by the school of logotherapy as stimulated by the pioneering work of Victor Frankl (1955, 1958, 1959, 1966, 1967, 1969, 1978, 1985, 1992, 2004, 2010) and as subsequently developed by others (see Guttmann, 1996; Lukas, 2000; Lukas \& Hirsch, 2002). Logotherapy focuses on the meaning of human existence as well as on how people search for such a meaning.

Purpose in life as conceptualized within logotherapy has been made accessible to empirical research by the Purpose in Life Test developed by Crumbaugh and Maholick (1964, 1969). This instrument has given rise to a fruitful stream of international research that establishes the central role of purpose in life in shaping a range of positive personal and social outcomes among diverse groups of people, including cancer patients (Wnuk et al., 2012) and the elderly (Gerwood et al., 1998). A number of studies and reviews provide general support for the reliability and validity of the Purpose in Life Test. It has generally demonstrated good convergent validity with measures of well-being and distress and good internal consistency reliability (see Jonsén et al., 2010; Litwinczuk \& Groh, 2007; Schulenberg \& Melton, 2010).

Robbins and Francis (2000) introduced the Purpose in Life Scale as an alternative measure of purpose in life. This instrument differs from the Purpose in Life Test in two important ways. First, the new instrument was designed to assess a much more tightly focused notion of purpose in life. Second, the new instrument comprised 12 Likert-type items rated on the conventional five-point scale, ranging from agree strongly through not certain to disagree strongly. In the foundation study, conducted among 517 firstyear undergraduate students, Robbins and Francis (2000) reported an alpha coefficient (Cronbach, 1951) of 0.90 with the correlations between each item and the sum of the other items varying between 0.41 and 0.76 , demonstrating good internal consistency reliability. The reliability and validity of this more recent instrument has been supported by, among others, Sillick and Cathcart (2014), Poteat et al. (2014), Crea (2016) and Francis et al. (2017d).

The measurement of purpose in life has been introduced to the science of clergy studies by Weinstein and Cleanthous (1996) among Protestant ministers and by Francis and Crea (2016) among Catholic priests. In a second study, Crea and Francis (in press) explored the effect of purpose in life scores among a sample of 156 Catholic priests and religious sisters in Italy on the two indices of positive affect (satisfaction in ministry) and negative affect (emotional exhaustion in ministry) proposed by the Francis Burnout Inventory. After controlling for personal factors (age and sex) and for psychological factors (emotionality and extraversion/introversion), the data demonstrated that higher scores on the Purpose in Life Scale were associated with both higher scores on the Satisfaction in Ministry Scale and lower scores on the Scale of Emotional Exhaustion in Ministry. These findings suggest that professional burnout and poor work-related psychological health among priests and religious sisters may, at least in part, be attributed to a poor sense of purpose in life. In light of this empirical evidence, Crea and Francis (in press) argued that therapeutic techniques developed by logotherapy may be relevant to addressing the problem of professional burnout and poor work-related psychological health among Catholic priests and religious sisters. 
Emotional intelligence was introduced by Salovey and Mayer (1990) and Mayer and Salovey (1993, 1995) and subsequently developed and popularized by Goleman (1995, 1998). Goleman maintains that emotional intelligence comprises two main components, styled as personal competence (how we handle ourselves) and as social competence (how we handle our relationships with others) and that each of these two main components comprises agreed subcomponents. According to Goleman's model of emotional intelligence, personal competence involves self-awareness (knowing one's emotional internal states, preferences, resources, and intuitions), self-regulation (managing one's emotional internal states, impulses, and resources), and motivation (emotional tendencies that guide or facilitate reaching goals). Social competence involves empathy (one's awareness of others' feelings, needs, and concerns) and social skills (one's adeptness at inducing desirable responses in others).

Emotional intelligence is both an illuminating and contested construct (Dulewicz et al., 2003). It is illuminating in the sense that it has been employed in research within a range of occupational settings and has been found to predict individual differences in work performance and in occupational health and well-being. It is contested in part because different traditions have defined and measured emotional intelligence in different ways.

The Schutte Emotional Intelligence Scale comprises 33 items that load on one principal factor, selected from an original pool of 62 items on data provided by 346 diverse participants recruited from a variety of settings in a metropolitan area in the southeastern United States. In the foundation study by Schutte et al. (1998), the scale recorded an alpha coefficient of 0.90 and a two-week test-retest reliability of 0.78 . The Schutte Emotional Intelligence Scale offers an attractive option for survey-style research in light of its brevity (33 items) and ease of scoring on a five-point Likert-type scale (agree strongly, agree, not certain, disagree, and disagree strongly).

The Schutte Emotional Intelligence Scale has been introduced to the science of clergy studies within the United Kingdom by a series of four studies: Francis et al. (2011a) among a sample of 154 individuals serving in leadership roles within local churches associated with the Newfrontiers network in England, including elders, staff, volunteer leaders, and highly committed members sharing in leadership; Randall (2014) among a sample of 156 Anglican clergy serving mainly in England in their fourteenth year of ministry; Hendron et al. (2014) among a sample of 226 clergy serving within one of the four main denominations based in Northern Ireland and in the Republic of Ireland that accepted both men and women into ministry; and Francis et al. (2019b) among a sample of 364 Anglican clergy serving in the Church in Wales.

In a further analysis of his data on 156 Anglican clergy serving in England, Randall (2015) explored the thesis that higher levels of emotional intelligence were associated with lower levels of burnout. Employing the Francis Burnout Inventory (Francis et al., 2005), Randall (2015) found that higher level of emotional intelligence were associated with both higher levels of satisfaction in ministry and lower levels of emotional exhaustion. Randall's finding that higher levels of emotional intelligence are associated with lower levels of burnout and better work-related psychological well-being among clergy is consistent with the findings of other studies employing the Maslach Burnout Inventory alongside the Schutte Emotional Intelligence Scale among other groups, including university professors (Iqbal \& Abbasi, 2013), nurses (Nel et al., 2013), healthcare professionals (Ünal, 2014; Năstasă \& Fărcaş, 2015) and teachers (Chan, 2006; Cohen \& Abedallah, 2015; Colomeischi, 2015; Platsidou, 2010). Randall (2015) concluded that these findings may offer a useful clue regarding ways in which better psychological health can be promoted among clergy. He 
argued that there may be real value in providing training in social and emotional competence as part of initial ministerial training and continuing ministerial development.

Intrinsic religiosity is a notion rooted in the pioneering work of Allport and Ross (1967), who distinguished in their conceptualization between the two forms of religious motivation that they contrasted as intrinsic orientation and as extrinsic orientation. The extended definitions of extrinsic religiosity and intrinsic religiosity advanced by Allport and Ross (1967) are worth citing in full. Here is their description of the extrinsic orientation.

Persons with this orientation are disposed to use religion for their own ends. The term is borrowed from axiology, to designate an interest that is held because it serves other, more ultimate interests. Extrinsic values are always instrumental and utilitarian. Persons with this orientation may find religion useful in a variety of ways to provide security and solace, sociability and distraction, status and self-justification. The embraced creed is lightly held or else selectively shaped to fit more primary needs. In theological terms the extrinsic type turns to God, but without turning away from self. (Allport \& Ross, 1967, p. 434)

Here is their description of the intrinsic orientation.

Persons of this orientation find their master motive in religion. Other needs, strong as they may be, are regarded as of less ultimate significance, and they are, so far as possible, brought into harmony with the religious beliefs and prescriptions. Having embraced a creed the individual endeavours to internalise it and follow it fully. It is in this sense that he lives his religion. (Allport \& Ross, 1967, p. 434)

Allport and Ross's (1967) intention in offering these definitions was not purely to be descriptive but also to be evaluative. According to their model, the intrinsic religious orientation profiled a more mature approach to religion than the extrinsic religious orientation. This theoretical perspective was validated by early empirical studies that found intrinsic religious orientation to be correlated with positive psychological correlates such as socially inclusive values whereas extrinsic religious orientation was found to be correlated with negative psychological correlates such as racial prejudice (for reviews, see Batson \& Ventis, 1982).

Religious orientation theory (extrinsic religiosity and intrinsic religiosity) has been introduced to the science of clergy studies by Francis and Crea (2016), who administered the New Indices of Religious Orientation (Francis, 2007) and the Purpose in Life Scale (Robbins \& Francis, 2000) to a sample of 155 Catholic priests serving in Italy. Taking purpose in life as a measure of well-being, Francis and Crea (2016) reported a positive association between intrinsic religiosity and well-being but no association between extrinsic religiosity and well-being.

\section{Research question}

Against this background, the present study has been designed to explore the effects of the dark triad and the bright trinity of psychological factors on professional burnout among priests and religious sisters in Italy when these two sets of variables are considered simultaneously. In the light of previous research in the field of clergy burnout, two sets of control variables will also be taken into account: personal factors and personality factors. Among personal factors, age emerges as the most important. Older clergy are 
less likely than younger clergy to report high levels of emotional exhaustion, either as the consequence of an aging effect (older clergy may have acquired better skills at managing psychological resources) or of a cohort effect (younger clergy recording high levels of emotional exhaustion may have exited from active ministry). While sex differences are less consistently reported, sex nonetheless remains a personal factor of significance. Among personality factors, neuroticism (or high emotionality) and introversion emerge as the most important. Clergy recording high scores on the measure of neuroticism (or emotionality) and low scores on extraversion are more likely to report high levels of emotional exhaustion (see, for example, Francis et al., 2012; Francis et al., 2004; Francis et al., 2013a; Francis et al., 2009; Francis \& Rutledge, 2000; Francis et al., 2008b; Randall, 2007; Rutledge \& Francis, 2004; Turton \& Francis, 2007). It is for these reasons that the present study controls for personal factors (age and sex) and for psychological factors (extraversion and emotionality) before exploring the effects of the dark triad and the bright trinity on measures of work-related psychological health.

\section{Method}

\section{Procedure}

In the context of an ongoing formation program conducted within the Pontifical Salesian University and by the Claretian Institute of the Theology of the Consecrated Life in Rome, participants were invited to complete a questionnaire covering issues relevant to the program. Participation in completing the questionnaire was voluntary, and responses to the questionnaire were confidential and anonymous. Full data were provided by 287 priests, religious brothers, and religious sisters from different parts of Italy. Ethical approval for the study was granted by the Ethics Committee of the Salesian Pontifical University, Rome.

\section{Participants}

Of the 287 participants, 130 were male, 157 were female; 87 were under the age of 35,59 were between the ages of 35 and 39, 74 were between the ages of 40 and 49, 62 were aged 50 or over, and five did not disclose their age; 97 were of Italian nationality, 184 were not of Italian nationality, and six did not disclose their nationality. Of the 130 men, 42 were diocesan priests, 65 were religious priests, 20 were religious brothers, and three were in formation. Of the 157 women, 154 were religious sisters, and three were in formation.

\section{Measures}

Personality factors were assessed by the Francis Psychological Type and Emotional Temperament Scales (FPTETS) developed from the instrument originally proposed by Francis (2005). This 50-item instrument comprises five sets of 10 forced-choice items related to emotionality and to each of the four components of psychological type: orientation (extraversion or introversion), perceiving process (sensing or intuition), judging process (thinking or feeling), and attitude toward the outer world (judging or perceiving). A number of studies have demonstrated this instrument to function well in church-related contexts. For example, Francis et al. (2008a) reported alpha coefficients of 0.83 for the EI scale, 0.76 for 
the SN scale, 0.73 for the TF scale, and 0.79 for the JP scale. Participants were presented each pair of characteristics and asked to "check the box next to that characteristic which is closer to the real you, even if you feel both characteristics apply to you. Tick the characteristics that reflect the real you, even if other people see you differently." The Italian translation of this instrument originated within the Salesian Pontifical University, employing the conventional practice of translation and back translation. Only the extraversion and emotionality scales were employed in the present analysis. The translated instrument achieved acceptable alpha coefficients (Francis \& Crea, 2016).

Professional burnout was assessed by the two scales proposed by the Francis Burnout Inventory (FBI: Francis et al., 2005). This 22-item instrument comprises the Scale of Emotional Exhaustion in Ministry (SEEM) and the Satisfaction in Ministry Scale (SIMS). Each item was assessed on a five-point scale ranging from agree strongly (5) to disagree strongly (1). The Italian translation achieved alpha coefficients of 0.79 for SIMS and 0.81 for SEEM (Francis \& Crea, 2015).

Purpose in life was assessed by the Purpose in Life Scale (PILS) developed by Robbins and Francis (2000), a 12-item instrument designed to assess a unidimensional construct. For example, a core item reads, "My personal existence is full of purpose." Each item was assessed on a five-point scale ranging from agree strongly (5) to disagree strongly (1). The Italian translation achieved an alpha coefficient of 0.90 (Crea, 2016).

Emotional intelligence was assessed by the 33-item Emotional Intelligence Scale proposed by Schutte et al. (1998). Each item was assessed on a five-point scale ranging from agree strongly (5) to disagree strongly (1). In a study among church leaders, Francis et al. (2011a), reported an alpha reliability coefficient of 0.81 .

Intrinsic religiosity was assessed by the Astley-Francis Scale of Attitude toward Theistic Faith (Astley et al., 2012). Adapted from the short form of the Francis Scale of Attitude toward Christianity (Francis et al., 1995), this instrument proposes seven items concerned with affective responses to God, places of worship, and prayer. Each item was assessed on a five-point scale ranging from agree strongly (5) to disagree strongly (1). Astley et al. (2012) reported an alpha coefficient of 0.95. Subsequent studies have recommended a reduction to five items (see Ceballos et al., 2015), and it is this form that is employed in the analyses. A series of studies link the affective dimension of religion closely with measures of intrinsic religiosity (see Francis \& Orchard, 1999).

The dark triad of Machiavellianism, subclinical narcissism, and subclinical psychopathy was assessed by the three nine-item measures proposed by the Short Dark Triad (Jones \& Paulhus, 2014). Each item was assessed on a five-point scale ranging from agree strongly (5) to disagree strongly (1). Jones and Paulhus (2014) reported the following alpha coefficients for these three measures: Machiavellianism, $\alpha=0.71$; subclinical narcissism, $\alpha=0.74$; and subclinical psychopathy, $\alpha=0.77$.

\section{Data analysis}

The data were analyzed by means of the SPSS statistical package using the reliability, correlation, factor, and regression routines. 


\section{Results}

The first step in data analysis explored the psychometric properties of the instruments. All three nine-item measures of the Italian translation of the Short Dark Triad performed poorly. The three scales were enhanced by the omission of poor-performing items, resulting in a set of three six-item measures. Table 1 presents the scale properties for the ten measures employed in the study: the three measures of the dark triad (Machiavellianism, subclinical narcissism, and subclinical psychopathy), the three measures of the bright trinity (emotional intelligence, purpose in life, and intrinsic religiosity), the two personality variables (extraversion and emotionality), and the two components of professional burnout (emotional exhaustion in ministry and satisfaction in ministry). These data demonstrate that the two components of professional burnout, the three components of the bright trinity, and the two personality variables all reach satisfactory levels of internal consistency reliability. The three measures of the dark triad display less satisfactory levels of internal consistency reliability.

The second step in data analysis explored the core associations among the variables. Table 2 presents the bivariate correlation coefficients between the two personal factors (age and sex), the two components of professional burnout (emotional exhaustion in ministry and satisfaction in ministry), the two personality variables (extraversion and emotionality), the three measures of the dark triad (Machiavellianism, subclinical narcissism, and subclinical psychopathy), and the three measures of the bright trinity (emotional intelligence, purpose in life, and intrinsic religiosity). Six features of these data deserve commentary.

First, three of the variables are significantly correlated with sex. Priests and male religious record higher levels of subclinical narcissism and of satisfaction in ministry. Female religious record higher scores of emotionality.

Second, two of the variables are significantly correlated with age. Older participants record lower scores of Machiavellianism and lower scores of extraversion.

Third, emotionality is significantly positively correlated with two of the three measures of the dark triad (Machiavellianism and subclinical psychopathy) and significantly negatively correlated with all three measures of the bright trinity (emotional intelligence, purpose in life, and intrinsic religiosity).

Fourth, extraversion is unrelated to any of the three measures of the dark triad but significantly positively correlated with all three measures of the bright trinity (emotional intelligence, purpose in life, and intrinsic religiosity).

Table 1 Scale Properties

\begin{tabular}{lrlrr}
\hline & N items & Alpha & Mean & \multicolumn{1}{c}{ SD } \\
\hline Machiavellianism & 6 & 0.63 & 12.66 & 3.90 \\
Narcissism & 6 & 0.58 & 15.01 & 3.47 \\
Psychopathy & 6 & 0.62 & 10.36 & 2.99 \\
Extraversion & 10 & 0.72 & 4.92 & 2.18 \\
Emotionality & 10 & 0.70 & 3.24 & 2.11 \\
Emotional exhaustion & 11 & 0.78 & 25.04 & 6.14 \\
Satisfaction in ministry & 11 & 0.84 & 43.15 & 5.41 \\
Emotional intelligence & 33 & 0.87 & 122.79 & 11.91 \\
Intrinsic religiosity & 5 & 0.77 & 23.71 & 1.93 \\
Purpose in life & 12 & 0.87 & 52.98 & 5.48 \\
\hline
\end{tabular}




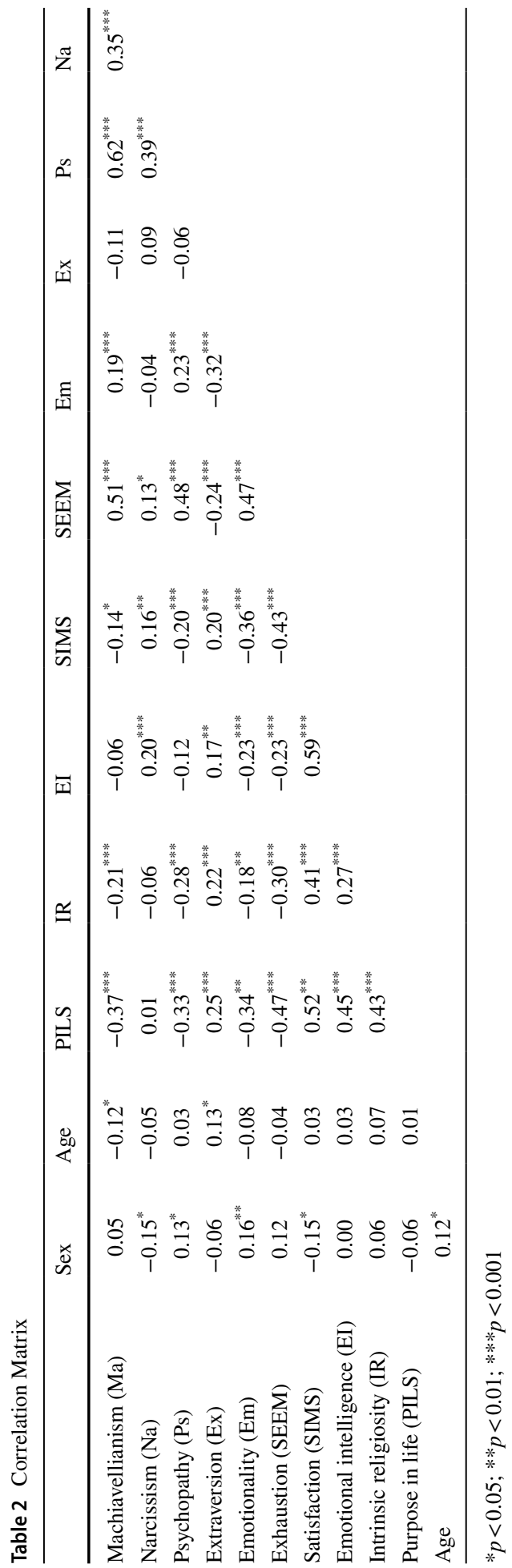


Fifth, satisfaction in ministry is significantly negatively correlated with two measures of the dark triad (Machiavellianism and subclinical psychopathy) but significantly positively correlated with the third measure of the dark triad (subclinical narcissism). Satisfaction in ministry is significantly positively correlated with all three measures of the bright trinity (emotional intelligence, purpose in life, and intrinsic religiosity). Higher levels of satisfaction in ministry are significantly correlated with higher extraversion scores and with lower emotionality scores.

Sixth, emotional exhaustion in ministry is significantly positively correlated with all three measures of the dark triad (Machiavellianism, subclinical narcissism, and subclinical psychopathy). Emotional exhaustion in ministry is significantly negatively correlated with all three measures of the bright trinity (emotional intelligence, purpose in life, and intrinsic religiosity). Higher levels of emotional exhaustion in ministry are significantly correlated with high emotionality scores and low extraversion scores.

The third step in the data analysis recognized that these complex patterns of interrelationship between pairs of variables demonstrate the wisdom of addressing the primary research question posed by the present study through regression analyses. Tables 3 and 4 present the two regression models for satisfaction in ministry and emotional exhaustion in ministry, respectively. In these two models, the predictor variables are entered in four steps. Model 1 enters personal factors (sex and age); model 2 adds personality factors (extraversion and emotionality); model 3 adds the dark triad (Machiavellianism, subclinical narcissism, and subclinical psychopathy); and model 4 adds the bright trinity (purpose in life, emotional intelligence, and intrinsic religiosity). For both regression models (satisfaction in ministry and emotional exhaustion in ministry), the increase in $\mathrm{R}^{2}$ shows that each of these four steps predicts additional variance within the incremental model. Two features of these data deserve commentary.

First, Table 3 demonstrates that the major proportion of variance accounted for in this model (concerned with satisfaction in ministry) is derived from the components of the bright trinity. When the three components of the bright trinity are entered into model 4 , none of the personal factors, none of the personality factors, and none of the factors of the dark triad record significant beta weights. Moreover, when the three components of the bright trinity are entered into the model, each of these three components contribute unique predictive power.

Second, Table 4 demonstrates that the major proportion of variance accounted for in this model (concerned with emotional exhaustion in ministry) is derived from the components of the dark triad and from the personality factors. When all four sets of factors are entered into model 4, the four strongest predictors of high levels of emotional exhaustion are derived from two components of the dark triad (high scores of Machiavellianism and high scores of subclinical psychopathy), from one component of the personality factors (high scores of emotionality), and from one component of the bright trinity (low scores of purpose in life).

\section{Conclusion}

The present study was designed to explore the effects of the dark triad of psychological factors and the effects of the bright trinity of psychological factors on professional burnout among priests and religious sisters in Italy when these two sets of variables are considered 
Table 3 Regression on Satisfaction in Ministry

\begin{tabular}{|c|c|c|c|c|}
\hline & Model 1 & Model 2 & Model 3 & Model 4 \\
\hline \multicolumn{5}{|l|}{ Personal factors } \\
\hline Sex & 0.12 & 0.04 & 0.00 & 0.08 \\
\hline Age & 0.05 & 0.00 & -0.03 & 0.03 \\
\hline \multicolumn{5}{|l|}{ Personality factors } \\
\hline Extraversion & & 0.11 & 0.09 & -0.03 \\
\hline Emotionality & & $-0.26^{* * *}$ & $-0.21^{* * *}$ & -0.11 \\
\hline \multicolumn{5}{|l|}{ Dark triad } \\
\hline Machiavellianism & & & -0.09 & 0.03 \\
\hline Narcissism & & & $0.23^{* * *}$ & 0.06 \\
\hline Psychopathy & & & -0.12 & 0.01 \\
\hline \multicolumn{5}{|l|}{ Bright trinity } \\
\hline Purpose in life & & & & $0.22^{* * * *}$ \\
\hline $\begin{array}{l}\text { Emotional intel- } \\
\text { ligence }\end{array}$ & & & & $0.41^{* * *}$ \\
\hline Intrinsic religiosity & & & & $0.22^{* * *}$ \\
\hline $\mathrm{R}^{2}$ & 0.02 & 0.11 & 0.16 & 0.48 \\
\hline$\Delta$ & 0.02 & $0.09^{* * *}$ & $0.05^{* *}$ & $0.33^{\text {*** }}$ \\
\hline
\end{tabular}

$* * p<0.01 ; * * * p<0.001$

simultaneously, after taking into account personal factors (sex and age) and personality factors (extraversion and emotionality). In this study, professional burnout was conceptualized in terms of the balanced affect model of work-related psychological health proposed by the Francis Burnout Inventory (Francis et al., 2005). This model maintains that burnout occurs when high levels of negative affect are not balanced by high levels of positive affect. In the Francis Burnout Inventory, negative affect is assessed by the Scale of Emotional Exhaustion in Ministry, while positive affect is assessed by the Satisfaction in Ministry Scale. In

Table 4 Regression Models on Emotional Exhaustion
Model $1 \quad$ Model $2 \quad$ Model $3 \quad$ Model 4

\begin{tabular}{lcccc}
\hline Personal factors & & & & \\
Sex & $-0.16^{*}$ & -0.05 & 0.00 & -0.02 \\
Age & -0.09 & -0.02 & 0.05 & 0.03 \\
Personality factors & & & & \\
Extraversion & & $-0.13^{*}$ & $-0.11^{*}$ & -0.07 \\
Emotionality & $0.38^{* * *}$ & $0.31^{* * *}$ & $0.26^{* * *}$ \\
Dark triad & & & \\
Machiavellianism & & & $0.32^{* * *}$ & $0.25^{* * *}$ \\
Narcissism & & & 0.00 & 0.05 \\
Psychopathy & & & $0.24^{* * *}$ & $0.20^{* * *}$ \\
Bright trinity & & & & $-0.18^{* * *}$ \\
Purpose in life & & & & -0.05 \\
Emotional intel- & & & & -0.07 \\
ligence & & & & 0.44 \\
Intrinsic religiosity & & 0.20 & $0.24^{* * *}$ & $0.04^{* * *}$ \\
$\mathrm{R}^{2}$ & 0.03 & $0.18^{* * *}$ & & \\
$\Delta$ & $0.03^{*}$ & & & \\
\hline$*$
\end{tabular}

$* p<0.05 ; * * p<0.01 ; * * * p<0.001$ 
this model, positive affect and negative affect are conceptualized not as opposite ends of a continuum but as two separate psychological systems. The relative independence of these two separate psychological systems is validated in the present study by the way in which the sets of predictor variables functioned in distinctive ways in the two regression models. One set of variables predicted greatest variance in positive affect, while another set of variables predicted greatest variance in negative affect.

In respect of negative affect the greatest variance was predicted by one personality factor (emotionality) and by two components of the dark triad (Machiavellianism and subclinical psychopathy). These variables are generally regarded as fairly fixed or stable. Screening for these variables may help to identify priests, religious brothers, and religious sisters who are most vulnerable to professional burnout. Such knowledge, coupled with self-awareness of vulnerability, may enable preventative strategies to be implemented to safeguard against the more debilitating consequences of professional burnout.

Regarding positive affect, the greatest variance was predicted by the cumulative effect of the three components of the bright trinity (purpose in life, emotional intelligence, and intrinsic religiosity). Each of these three factors is thought to be amenable to therapeutic, educational, or spiritual intervention. Purpose in life rests at the heart of logotherapy and is considered to be subject to therapeutic intervention. Emotional intelligence is considered to be a developmental factor and is subject to educational intervention. Intrinsic religiosity rests at the heart of vocation to the priestly life and to the religious life and is subject to spiritual and formational intervention. Although ecclesial authorities may be relatively powerless to address the detrimental effects of emotionality, Machiavellianism and subclinical psychopathy on the levels of emotional exhaustion experienced by priests, religious brothers, and religious sisters, ecclesial authorities may be better placed to implement the therapeutic, educational, and spiritual and formational interventions that may enhance levels of purpose in life, emotional intelligence, and intrinsic religiosity. In turn, these features of the bright trinity seem to be associated with enhanced sense of satisfaction in ministry.

According to the balanced affect model of professional burnout and clergy work-related psychological well-being, enhancing satisfaction in ministry ameliorates the negative consequences of emotional exhaustion in ministry. To some extent, the negative effects of high levels of emotional exhaustion in ministry are reduced by high levels of satisfaction in ministry (Francis et al., 2011b; Francis et al., 2017a, b, c; Francis et al., 2019a; Village et al., 2018).

This study has made an original contribution to theorizing the dynamics of clergy professional burnout and work-related psychological health by drawing together the balanced affect model of professional burnout as assessed by the Francis Burnout Inventory (Francis et al., 2005), the three components of the dark triad as assessed by a modified version of the Short Dark Triad (Jones \& Paulhus, 2014), and three variables classified as the bright trinity: purpose in life as assessed by the Purpose in Life Scale (Robbins \& Francis, 2000), emotional intelligence as assessed by the Emotional Intelligence Scale (Schutte et al., 1998), and intrinsic religiosity as assessed by the Astley-Francis Scale of Attitude toward Theistic Faith (Astley et al., 2012). This study has modeled and tested this theory on data provided by 287 Catholic priests and religious sisters surveyed in Italy.

The limitations with this study concern the reliance on one specific group of religious professionals, on a short measure of the three components of the dark triad that failed to generate a high level of internal consistency reliability among religious professionals, and on a proxy measure for intrinsic religiosity. These limitations need to be addressed in future studies by replicating and extending the research among other groups of clergy and 
religious professionals, by employing longer measures of the three components of the dark triad, and by employing an established measure of intrinsic religiosity.

Open Access This article is licensed under a Creative Commons Attribution 4.0 International License, which permits use, sharing, adaptation, distribution and reproduction in any medium or format, as long as you give appropriate credit to the original author(s) and the source, provide a link to the Creative Commons licence, and indicate if changes were made. The images or other third party material in this article are included in the article's Creative Commons licence, unless indicated otherwise in a credit line to the material. If material is not included in the article's Creative Commons licence and your intended use is not permitted by statutory regulation or exceeds the permitted use, you will need to obtain permission directly from the copyright holder. To view a copy of this licence, visit http://creativecommons.org/licenses/by/4.0/.

\section{References}

Allport, G. W., \& Ross, J. M. (1967). Personal religious orientation and prejudice. Journal of Personality and Social Psychology, 5, 432-443. https://doi.org/10.1037/h0021212

Astley, J., Francis, L. J., \& Robbins, M. (2012). Assessing attitude towards religion: The Astley-Francis Scale of Attitude toward Theistic Belief. British Journal of Religious Education, 34, 183-193. https:// doi.org/10.1080/01416200.2011.614735

Barber, N. (1998). Sex differences in disposition towards kin, security of adult attachment, and sociosexuality as a function of parental divorce. Evolution and Human Behaviour, 19, 125-132. https://doi.org/ $10.1016 / \mathrm{S} 1090-5138(98) 00004-\mathrm{X}$

Barnard, L. K., \& Curry, J. F. (2012). The relationship of clergy burnout to self-compassion and other personality dimensions. Pastoral Psychology, 61, 149-163. https://doi.org/10.1007/s11089-011-0377-0

Batson, C. D., \& Ventis, W. L. (1982). The religious experience: A social psychological perspective. Oxford University Press.

Beebe, R. S. (2007). Predicting burnout, conflict management style, and turnover among clergy. Journal of Career Assessment, 15, 257-275. https://doi.org/10.1177/1069072706298157

Brewster, C. E., Francis, L. J., \& Robbins, M. (2011). Maintaining a public ministry in rural England: Workrelated psychological health and psychological type among Anglican clergy serving in multi-church benefices. In H-G. Ziebertz \& L. J. Francis (Eds.), The public significance of religion (pp. 241-265). Leiden: Brill. https://doi.org/10.1163/ej.9789004207066.i-495.90

Bushman, B. J., \& Baumeister, R. F. (1998). Threatened egotism, narcissism, self-esteem, and direct and displaced aggression: Does self-love or self-hate lead to violence? Journal of Personality and Social Psychology, 75, 219-229. https://doi.org/10.1037/0022-3514.75.1.219

Bushman, B. J., Bonacci, A. M., van Dijk, M., \& Baumeister, R. F. (2003). Narcissism, sexual refusal, and aggression: Testing a narcissistic reactance model of sexual coercion. Journal of Personality and Social Psychology, 84, 1027-1040. https://doi.org/10.1037/0022-3514.84.5.1027

Büssing, A., Baumann, K., Jacobs, C., \& Frick, E. (2017). Spiritual dryness in Catholic priests: Internal resources as possible buffers. Psychology of Religion and Spirituality, 9, 46-55. https://doi.org/10. $1037 /$ rel0000063

Buys, C., \& Rothman, S. (2010). Burnout and engagement of reformed church ministers. SA Journal of Industrial Psychology, 36(1), Art. \# 825, 11 pages. https://doi.org/10.4102/sajip.v36i1.825

Ceballos, G. A., Suescun, J. D., Oviedo, H. C., Herazo, E., \& Campo-Arias, A. (2015). Five-item Francis scale of attitude toward Christianity: Construct and nomological validity and internal consistency among Colombian college students. Journal of Beliefs and Values, 36, 347-353. https://doi.org/10. 1080/13617672.2015.1099939

Chan, D. W. (2006). Emotional intelligence and components of burnout among Chinese secondary school teachers in Hong Kong. Teaching and Teacher Education, 22, 1042-1054. https://doi.org/10.1016/j. tate.2006.04.005

Chan, K., \& Chen, M. (2019). Experiences of stress and burnout among pastors in China. Journal of Pastoral Care and Counseling, 73, 232-237. https://doi.org/10.1177/1542305019886533

Chandler, D. J. (2009). Pastoral burnout and the impact of personal spiritual renewal, rest-taking, and support system practices. Pastoral Psychology, 58, 273-287. https://doi.org/10.1007/s11089-008-0184-4 
Christie, R., \& Geis, F. L. (1970). Studies in Machiavellianism. Academic Press. https://doi.org/10.1016/ B978-0-12-174450-2.50006-3.

Cohen, A., \& Abedallah, M. (2015). The mediating role of burnout on the relationship of emotional intelligence and self-efficacy with OCB and performance. Management Research Review, 38, 2-28. https:// doi.org/10.1108/MRR-10-2013-0238

Colomeischi, A. A. (2015). Teachers' burnout in relation with their emotional intelligence and personality traits. Procedia: Social and Behavioral Sciences, 180, 1067-1073. https://doi.org/10.1016/j.sbspro. 2015.02.207

Crea, G. (2016). The psychometric properties of the Italian translation of the Purpose in Life Scale (PILS) in Italy among a sample of Italian adults. Mental Health Religion and Culture, 19, 858-896. https:// doi.org/10.1080/13674676.2016.1277988

Crea, G., \& Francis, L. J. (2015). Professional burnout among Catholic religious sisters in Italy: An empirical enquiry exploring the protective role of quality of community life. Research in the Social Scientific Study of Religion, 26, 266-290. https://doi.org/10.1163/9789004299436_018

Crea, G., \& Francis, L. J. (in press). Purpose in life as protection against professional burnout among Catholic priests and religious in Italy: Testing the insights of logotherapy. Pastoral Psychology.

Cronbach, L. J. (1951). Coefficient alpha and the internal structure of tests. Psychometrika, 16, $297-334$. https://doi.org/10.1007/BF02310555

Crumbaugh, J. C., \& Maholick, L. T. (1964). An experimental study in existentialism: The psychometric approach to Frankl's concept of noogenic neurosis. Journal of Clinical Psychology, 20, 200-207. https://doi.org/10.1002/1097-4679(196404)20:2\%3c200::AID-JCLP2270200203\%3e3.0.CO;2-U

Crumbaugh, J. C., \& Maholick, L. T. (1969). Manual of instructions for the Purpose in Life Test (PIL). . Psychometric Affiliates. https://doi.org/10.1037/t01175-000

Dias, R. J. L. (2019). Burnout among Catholic priests in Brazil: Prevalence and associated factors. Interação em Psicologia, 23, 255-267. https://doi.org/10.5380/psi.v23i02.65076

Doolittle, B. R. (2007). Burnout and coping among parish-based clergy. Mental Health, Religion and Culture, 10, 31-38. https://doi.org/10.1080/13674670600857591

Doolittle, B. R. (2010). The impact of behaviours upon burnout among parish-based clergy. Journal of Religion and Health, 49, 88-95. https://doi.org/10.1007/s10943-008-9217-7

Dulewicz, S. V., Higgs, M., \& Slaski, M. (2003). Measuring emotional intelligence: Content, construct and criterion-related validity. Journal of Managerial Psychology, 18, 405-420. https://doi.org/10.1108/ 02683940310484017

Durkee-Lloyd, J. (2016). The relationship between work-related psychological health and psychological type among Canadian Baptist clergy: A research report. Journal of Empirical Theology, 29, 201-211. https://doi.org/10.1163/15709256-12341343

Evers, W., \& Tomic, W. (2003). Burnout among Dutch Reformed pastors. Journal of Psychology and Theology, 31, 329-338. https://doi.org/10.1177/009164710303100403

Forth, A. E., Brown, S. L., Hart, S. D., \& Hare, R. D. (1996). The assessment of psychopathy in male and female noncriminals: Reliability and validity. Personality and Individual Differences, 20, 531-543. https://doi.org/10.1016/0191-8869(95)00221-9

Francis, L. J. (2005). Faith and psychology: Personality, religion and the individual. . Darton, Longman and Todd.

Francis, L. J. (2007). Introducing the New Indices of Religious Orientation (NIRO): Conceptualisation and measurement. Mental Health, Religion and Culture, 10, 585-602. https://doi.org/10.1080/13674670601035510

Francis, L. J. (2018). Healthy leadership: The science of clergy work-related psychological health. In R. Brouwer (Ed.), The future of lived religious leadership. (pp. 116-134). VU University Press.

Francis, L. J., Craig, C. L., \& Hall, G. (2008a). Psychological type and attitude toward Celtic Christianity among committed churchgoers in the United Kingdom: An empirical study. Journal of Contemporary Religion, 23, 181-191. https://doi.org/10.1080/13537900802024543.

Francis, L. J., \& Crea, G. (2015). Work-related psychological health and psychological type: A study among Catholic priests in Italy. Mental Health, Religion and Culture, 18, 593-604. https://doi.org/10.1080/ 13674676.2014.963996

Francis, L. J., \& Crea, G. (2016). The relationship between priestly motivational styles and personal wellbeing in ministry: Exploring the connection between religious orientation and purpose in life among Catholic priests serving in Italy. Review of Religious Research, 58, 219-228. https://doi.org/10.1007/ s13644-015-0242-1

Francis, L. J., Crea, G., \& Laycock, P. (2017a). Work-related psychological health among Catholic religious in Italy: Testing the balanced affect model. Journal of Empirical Theology, 30, 236-252. https://doi. org/10.1163/15709256-12341357. 
Francis, L. J., Gubb, S., \& Robbins, M. (2012). Work-related psychological health and psychological type among lead elders within the Newfrontiers network of churches in the United Kingdom. Journal of Prevention and Intervention in the Community, 40, 233-245. https://doi.org/10.1080/10852352.2012. 680422

Francis, L. J., Kaldor, P., Robbins, M., \& Castle, K. (2005). Happy but exhausted? Work-related psychological health among clergy. Pastoral Sciences, 24, 101-120.

Francis, L. J., Laycock, P., \& Brewster, C. E. (2015). The burdens of rural ministry: Identifying and exploring the correlates of five causes of stress among rural Anglican clergy serving in multi-parish benefices. Research in the Social Scientific Study of Religion, 26, 218-236. https://doi.org/10.1163/9789004299436_015

Francis, L. J., Laycock, P., \& Brewster, C. (2017b). Work-related psychological wellbeing: Testing the balanced affect model among Anglican clergy. Religions, 8(118), 1-11. https://doi.org/10.3390/rel8070118.

Francis, L. J., Laycock, P., \& Crea, G. (2017c). Assessing clergy work-related psychological health: Reliability and validity of the Francis Burnout Inventory. Mental Health, Religion and Culture, 20, 911-921. https://doi.org/10.1080/13674676.2017.1373333.

Francis, L. J., Laycock, P., \& Ratter, H. (2019a). Testing the Francis Burnout Inventory among Anglican clergy in England. Mental Health, Religion and Culture, 22, 1057-1067. https://doi.org/10.1080/ 13674676.2019.1644304

Francis, L. J., Lewis, J. M., Philipchalk, R., Lester, D., \& Brown, L. B. (1995). Reliability and validity of a short scale of attitude toward Christianity among students in the UK, USA, Australia and Canada. Psychological Reports, 77, 431-434. https://doi.org/10.2466/pr0.1995.77.2.431

Francis, L. J., Louden, S. H., \& Rutledge, C. J. F. (2004). Burnout among Roman Catholic parochial clergy in England and Wales: Myth or reality? Review of Religious Research, 46, 5-19. https://doi.org/10. $2307 / 3512249$

Francis, L. J., \& Orchard, A. (1999). The relationship between the Francis Scale of Attitude toward Christianity and measures of intrinsic, extrinsic and quest religiosity. Pastoral Psychology, 47, 365-371. https://doi. org/10.1023/A:1021310319890

Francis, L. J., Payne, V. J., \& Emslie, N. (2019b). Just how emotionally intelligent are religious leaders in Britain? A study among Anglican clergy in Wales. Pastoral Psychology, 68, 261-269. https://doi.org/ 10.1007/s11089-018-0845-x

Francis, L. J., Payne, V. J., \& Robbins, M. (2013a). Psychological type and susceptibility to burnout: A study among Anglican clergymen in Wales. In B. R. Doolittle (Ed.), Psychology of burnout: New research (pp. 179-192). New York: Nova Science. https://doi.org/10.1037/e591202013-001

Francis, L. J., Robbins, M., Kaldor, K., \& Castle, K. (2009). Psychological type and work-related psychological health among clergy in Australia, England and New Zealand. Journal of Psychology and Christianity, 28, 200-212.

Francis, L. J., Robbins, M., \& Wulff, K. (2013b). Assessing the effectiveness of support strategies in reducing professional burnout among clergy serving in the Presbyterian Church (USA). Practical Theology, 6, 319-331. https://doi.org/10.1179/1756073X13Z.00000000021.

Francis, L. J., Robbins, M., \& Wulff, K. (2013c). Are clergy serving yoked congregations under greater stress? A study among clergy serving in the Presbyterian Church (USA). Stress and Health, 29, 113116. https://doi.org/10.1002/smi.2434

Francis, L. J., \& Rutledge, C. J. F. (2000). Are rural clergy in the Church of England under greater stress? A study in empirical theology. Research in the Social Scientific Study of Religion, 11, 173-191.

Francis, L. J., Ryland, A., \& Robbins, M. (2011a). Emotional intelligence among church leaders: Applying the Schutte Emotional Intelligence Scale within Newfrontiers. In S. Boag \& N. Tiliopoulos (Eds.), Personality and individual differences: Theory, assessment, and application (pp. 141-149). Nova Science.

Francis, L. J., Village, A., \& Parker, S. G. (2017d). Exploring the trajectory of personal, moral and spiritual values of 16- to 18-year-old students taking religious studies at A level in the UK. Journal of Beliefs and Values, 38, 18-31. https://doi.org/10.1080/13617672.2016.1232567

Francis, L. J., Village, A., Robbins, M., \& Wulff, K. (2011b). Work-related psychological health among clergy serving in the Presbyterian Church (USA): Testing the idea of balanced affect. Review of Religious Research, 53, 9-22. https://doi.org/10.1007/s13644-011-0003-8.

Francis, L. J., Wulff, K., \& Robbins, M. (2008b). The relationship between work-related psychological health and psychological type among clergy serving in the Presbyterian Church (USA). Journal of Empirical Theology, 21, 166-182. https://doi.org/10.1163/157092508X349854.

Frankl, V. E. (1955). The doctor of the soul: An introduction to logotherapy. . Alfred A Knopf.

Frankl, V. E. (1958). The will to meaning. Journal of Pastoral Care, 12, 82-88.

Frankl, V. E. (1959). From death-camp to existentialism. . Beacon Press. 
Frankl, V. E. (1966). Logotherapy and existential analysis: A review. American Journal of Psychotherapy, 20, 252-260. https://doi.org/10.1176/appi.psychotherapy.1966.20.2.252

Frankl, V. E. (1967). Psychotherapy and existentialism. . Washington Square Press. https://doi.org/10.1037/ h0087982

Frankl, V. E. (1969). The will to meaning: Foundations and applications of logotherapy. . World Publishing.

Frankl, V. E. (1978). The unheard cry for meaning: Psychotherapy and humanism. . Simon and Schuster.

Frankl, V. E. (1985). Man's search for meaning. . Washington Square Press.

Frankl, V. E. (1992). Man's search for meaning: An introduction to logotherapy. (4th ed.). Beacon Press.

Frankl, V. E. (2004). The doctor and the soul: From psychotherapy to logotherapy. Souvenir.

Frankl, V. E. (2010). The feeling of meaninglessness: A challenge to psychotherapy and philosophy. . Marquette University Press.

Furnham, A., Richards, S. C., \& Paulhus, D. L. (2013). The dark triad of personality: A 10-year review. Social and Personality Compass, 7, 199-216. https://doi.org/10.1111/spc3.12018

Gerwood, J. B., LeBlanc, M., \& Piazza, N. (1998). The Purpose-in-Life Test and religious denomination: Protestant and Catholic scores in an elderly population. Journal of Clinical Psychology, 54, 49-53. https://doi.org/10.1002/(SICI)1097-4679(199801)54:1\%3c49::AID-JCLP5\%3e3.0.CO;2-P

Golden, J., Piedmont, R. L., Ciarrocchi, J. W., \& Rodgerson, T. (2004). Spirituality and burnout: An incremental validity study. Journal of Psychology and Theology, 32, 115-125. https://doi.org/10.1177/ 009164710403200204

Goleman, D. (1995). Emotional intelligence. . Bantam Books.

Goleman, D. (1998). Working with emotional intelligence. . Bloomsbury. https://doi.org/10.1002/ltl.40619981008

Guttmann, D. (1996). Logotherapy for helping professionals: Meaningful social work. . Springer.

Hare, R. D. (1985). Comparison of procedures for the assessment of psychopathy. Journal of Consulting and Clinical Psychology, 53, 7-16. https://doi.org/10.1037/0022-006X.53.1.7

Hare, R. D., \& Neumann, C. S. (2008). Psychopathy as a clinical and empirical construct. Annual Review of Clinical Psychology, 4, 217-241. https://doi.org/10.1146/annurev.clinpsy.3.022806.091452

Hendron, J. A., Irving, P., \& Taylor, B. J. (2014). The emotionally intelligent ministry: Why it matters. Mental Health, Religion and Culture, 17, 470-478. https://doi.org/10.1080/13674676.2013.848424

Herrera, H. L., Pedrosa, I., Galindo, M. P. V., Suárez-Álvarez, J., Villardón, M. P. G., \& García-Cueto, E. (2014). Multivariate analysis of burnout syndrome in Latin American priests. Psicothema, 26, 227-234.

Iqbal, F., \& Abbasi, F. (2013). Relationship between emotional intelligence and job burnout among university professors. Asian Journal of Social Sciences and Humanities, 2, 219-229.

Jonason, P. K., \& Webster, G. D. (2010). The Dirty Dozen: A concise measure of the dark triad. Psychological Assessment, 22, 420-432. https://doi.org/10.1037/a0019265

Jones, D. N., \& Paulhus, D. L. (2010). Different provocations trigger aggression in narcissists and psychopaths. Social and Personality Psychology Science, 1, 12-18. https://doi.org/10.1177/1948550609347591

Jones, D. N., \& Paulhus, D. L. (2011a). The role of impulsivity in the dark triad of personality. Personality and Individual Differences, 51, 670-682. https://doi.org/10.1016/j.paid.2011.04.011.

Jones, D. N., \& Paulhus, D. L. (2011b). Differentiating the dark triad within the interpersonal circumplex. In L. M. Horowitz \& S. Strack (Eds.), Handbook of interpersonal psychology: Theory, research, assessment, and therapeutic interventions (pp. 249-268). New York: Wiley. https://doi.org/10.1002/ 9781118001868.ch15

Jones, D. N., \& Paulhus, D. L. (2014). Introducing the Short Dark Triad (SD3): A brief measure of dark personality traits. Assessment, 21, 28-41. https://doi.org/10.1177/1073191113514105

Jonsén, E., Fagerström, L., Lundman, B., Nygren, B., Vähäkangas, M., \& Strandberg, G. (2010). Psychometric properties of the Swedish version of the Purpose in Life Scale. Scandinavian Journal of Caring Sciences, 24, 41-48. https://doi.org/10.1111/j.1471-6712.2008.00682.x

Joseph, E., Corveleyn, J., Luyten, P., \& de Witte, H. (2010). Does commitment to celibacy lead to burnout or enhanced engagement? A Study among the Indian Catholic clergy. European Journal of Mental Health, 5, 187-204. https://doi.org/10.1556/EJMH.5.2010.2.2

Joseph, N. J., Luyten, P., Corveleyn, J., \& de Witte, H. (2011). The relationship between personality, burnout, and engagement among the Indian clergy. International Journal for the Psychology of Religion, 21, 276-288. https://doi.org/10.1080/10508619.2011.607412

Kernberg, O. (1975). Borderline conditions and pathological narcissism. . Jason Aronson.

Kohut, H. (1978). Discussion of "The Function of the Analyst in the Therapeutic Process" by Samuel D. Lipton. In P. H. Ornstein (Ed.), The search for the self: Selected writings of Heinz Kohut: 19501978 (Vol. 1, pp. 159-166). New York: International Universities Press.

Küçüksüleymanoğlu, R. (2013). Occupational burnout levels of Turkish imams. Review of Religious Research, 55, 27-42. https://doi.org/10.1007/s13644-012-0057-2 
Lilienfeld, S. O., \& Andrews, B. P. (1996). Development and preliminary validation of a self-report measure of psychopathic personality traits in non-criminal populations. Journal of Personality Assessment, 66, 488-524. https://doi.org/10.1207/s15327752jpa6603_3

Litwinczuk, K. M., \& Groh, C. J. (2007). The relationship between spirituality, purpose in life, and wellbeing in HIV-positive persons. Journal of the Association of Nurses in AIDS Care, 18, 13-22. https://doi.org/10.1016/j.jana.2007.03.004

Lukas, E. (2000). Logotherapy textbook: Meaning-centered therapy. . Liberty Press.

Lukas, E., \& Hirsch, B. Z. (2002). Logotherapy. interpersonal/humanistic/existentialIn F. W. Kaslow, R. F. Massey, \& S. D. Massey (Eds.), Comprehensive handbook of psychotherapy. (Vol. 3, pp. 333-356). John Wiley \& Sons.

Machiavelli, N. (1981). The prince. New York: Bantam Classics. (Original work published 1513)

Maslach, C., \& Jackson, S. E. (1985). The role of sex and family variables in burnout. Sex Roles, 12, 837-851. https://doi.org/10.1007/BF00287876

Mayer, J. D., \& Salovey, P. (1993). The intelligence of emotional intelligence. Intelligence, 17, 433-442. https://doi.org/10.1016/0160-2896(93)90010-3

Mayer, J. D., \& Salovey, P. (1995). Emotional intelligence and the construction and regulation of feelings. Applied and Preventative Psychology, 4, 197-208. https://doi.org/10.1016/S0962-1849(05)80058-7

Miner, M. H. (2007a). Changes in burnout over the first 12 months in ministry: Links with stress and orientation to ministry. Mental Health, Religion and Culture, 10, 9-16. https://doi.org/10.1080/ 13674670600841819

Miner, M. H. (2007b). Burnout in the first year of ministry: Personality and belief style as important predictors. Mental Health, Religion and Culture, 10, 17-29. https://doi.org/10.1080/13694670500378017

Miner, M. H., Sterland, S., \& Dawson, M. (2009). Orientation to the demands of ministry: Construct validity and relationship with burnout. Review of Religious Research, 50, 463-479.

Morf, C. C., \& Rhodewalt, F. (2001a). Expanding the dynamic self-regulatory processing model of narcissism: Research directions for the future. Psychological Inquiry, 12, 243-251. https://doi.org/10. 1207/S15327965PLI1204_3.

Morf, C. C., \& Rhodewalt, F. (2001b). Unraveling the paradoxes of narcissism: A dynamic self-regulatory processing model. Psychological Inquiry, 12, 177-196. https://doi.org/10.1207/S15327965PLI1204_1

Năstasă, L-E., \& Fărcaş, A. D. (2015). The effect of emotional intelligence on burnout in healthcare professionals. Procedia: Social and Behavioral Sciences, 187, 78-82. https://doi.org/10.1016/j. sbspro.2015.03.015

Nel, J. A., Jonker, C. S., \& Rabie, T. (2013). Emotional intelligence and wellness among employees working in the nursing environment. Journal of Psychology in Africa, 23, 195-203. https://doi. org/10.1080/14330237.2013.10820615

Parker, P. D., \& Martin, A. J. (2011). Clergy motivation and occupational well-being: Exploring a quadripolar model and its role in predicting burnout and engagement. Journal of Religion and Health, 50, 656-674. https://doi.org/10.1007/s10943-009-9303-5

Paulhus, D. L., \& Jones, D. N. (2017). Duplicity among the dark triad: Three faces of deceit. Journal of Personality and Social Psychology, 113, 329-342. https://doi.org/10.1037/pspp0000139

Paulhus, D. L., \& Williams, K. M. (2002). The dark triad of personality: Narcissism, Machiavellianism, and psychopathy. Journal of Research in Personality, 36, 556-563. https://doi.org/10.1016/S00926566(02)00505-6

Platsidou, M. (2010). Trait emotional intelligence of Greek special education teachers in relation to burnout and job satisfaction. School Psychology International, 31, 60-76. https://doi.org/10.1177/0143034309360436

Poteat, V. P., Yoshikawa, H., Calzo, J. P., Gray, M. L., DiGiovanni, C. D., Lipkin, A., \& Carder, K. (2014). Closeness to God among those doing God's work: A spiritual well-being measure for clergy. Journal of Religion and Health, 53, 878-894. https://doi.org/10.1007/s10943-013-9682-5

Raj, A., \& Dean, K. E. (2005). Burnout and depression among Catholic priests in India. Pastoral Psychology, 54, 157-171. https://doi.org/10.1007/s11089-005-6200-z

Randall, K. (2007). Examining the relationship between burnout and age among Anglican clergy in England and Wales. Mental Health, Religion and Culture, 10, 39-46. https://doi.org/10.1080/13674670601012303

Randall, K. (2013). Clergy burnout: Two different measures. Pastoral Psychology, 62, 333-341. https://doi. org/10.1007/s11089-012-0506-4

Randall, K. J. (2014). Emotional intelligence: What is it, and do Anglican clergy have it? Mental Health, Religion and Culture, 17, 262-270. https://doi.org/10.1080/13674676.2013.796916

Randall, K. J. (2015). Emotional intelligence and clergy work-related psychological health among Anglican clergy in England and Wales. Research in the Social Scientific Study of Religion, 26, 291-301. https:// doi.org/10.1163/9789004299436_019 
Raskin, R., \& Hall, C. S. (1979). A Narcissistic Personality Inventory. Psychological Reports, 45, 590. https://doi.org/10.2466/pr0.1979.45.2.590

Robbins, M., \& Francis, L. J. (2000). Religion, personality and well-being: The relationship between church attendance and purpose in life among undergraduates attending an Anglican College in Wales. Journal of Research in Christian Education, 9, 223-238. https://doi.org/10.1080/10656210009484908

Robbins, M., \& Francis, L. J. (2010). Work-related psychological health among Church of England clergywomen: Individual differences and psychological type. Review of Religious Research, 52, 57-71.

Robbins, M., Francis, L. J., \& Powell, R. (2012). Work-related psychological health among clergywomen in Australia. Mental Health, Religion and Culture, 15, 933-944. https://doi.org/10.1080/13674676. 2012.698044

Rodgerson, T. E., \& Piedmont, R. L. (1998). Assessing the incremental validity of the Religious ProblemSolving Scale in the prediction of clergy burnout. Journal for the Scientific Study of Religion, 37, 517-527. https://doi.org/10.2307/1388058

Rossetti, S. J., \& Rhoades, C. J. (2013). Burnout in Catholic clergy: A predictive model using psychological and spiritual variables. Psychology of Religion and Spirituality, 5, 335-341. https://doi.org/10.1037/ a0033639

Rutledge, C. J. F., \& Francis, L. J. (2004). Burnout among male Anglican parochial clergy in England: Testing a modified form of the Maslach Burnout Inventory. Research in the Social Scientific Study of Religion, 15, 71-93.

Salovey, P., \& Mayer, J. D. (1990). Emotional intelligence. Imagination, Cognition and Personality, 9, 185211. https://doi.org/10.2190/DUGG-P24E-52WK-6CDG

Schulenberg, S., \& Melton, A. (2010). A confirmatory factor-analytic evaluation of the purpose in life test: Preliminary psychometric support for a replicable two-factor model. Journal of Happiness Studies, 11, 95-111. https://doi.org/10.1007/s10902-008-9124-3

Schutte, N. S., Malouff, J. M., Hall, L. E., Haggerty, D. J., Cooper, J. T., Golden, C. J., \& Dornheim, L. (1998). Development and validation of a measure of emotional intelligence. Personality and Individual Differences, 25, 167-177. https://doi.org/10.1016/S0191-8869(98)00001-4

Sillick, W. J., \& Cathcart, S. (2014). The relationship between religious orientation and happiness: The mediating role of purpose in life. Mental Health, Religion and Culture, 17, 494-507. https://doi.org/ 10.1080/13674676.2013.852165

Stanton-Rich, H. M., \& Iso-Ahola, S. E. (1998). Burnout and leisure. Journal of Applied Social Psychology, 28, 1931-1950. https://doi.org/10.1111/j.1559-1816.1998.tb01354.x

Strümpfer, D. J. W., \& Bands, J. (1996). Stress among clergy: An exploratory study on South African Anglican priests. South African Journal of Psychology, 26(2), 67-75. https://doi.org/10.1177/008124639602600201

Tillich, P. (1952). The courage to be. . Yale University Press.

Turton, D. W., \& Francis, L. J. (2007). The relationship between attitude toward prayer and professional burnout among Anglican parochial clergy in England: Are praying clergy healthier clergy? Mental Health, Religion and Culture, 10, 61-74. https://doi.org/10.1080/13674670601012246

Ünal, Z. M. (2014). The contribution of emotional intelligence on the components of burnout: The case of health care sector professionals. Electronic Journal of Business Ethics and Organization Studies, 19, 27-34. http://ejbo.jyu.fi/

Vazire, S., \& Funder, D. C. (2006). Impulsivity and the self-defeating behaviour of narcissists. Personality and Social Psychology Review, 10, 154-165. https://doi.org/10.1207/s15327957pspr1002_4

Vicente-Galindo, M. P., López-Herrera, H., Pedrosa, I., Suárez-Álvarez, J., Galindo-Villardón, M. P., \& García-Cueto, E. (2017). Estimating the effect of emotional intelligence in wellbeing among priests. International Journal of Clinical and Health Psychology, 17, 46-55. https://doi.org/10.1016/j.ijchp. 2016.10.001

Village, A., Payne, V. J., \& Francis, L. J. (2018). Testing the balanced affect model of clergy work-related psychological health: Replication among Anglican clergy in Wales. Rural Theology, 16, 93-100. https://doi.org/10.1080/14704994.2018.1519918

Virginia, S. G. (1998). Burnout and depression among Roman Catholic secular, religious, and monastic clergy. Pastoral Psychology, 47, 49-67. https://doi.org/10.1023/A:1022944830045

Warner, J., \& Carter, J. D. (1984). Loneliness, marital adjustment and burnout in pastoral and lay persons. Journal of Psychology and Theology, 12, 125-131. https://doi.org/10.1177/009164718401200206

Weinstein, L., \& Cleanthous, C. C. (1996). A comparison of Protestant ministers and parishioners on expressed purpose in life and intrinsic religious motivation. Psychology: A journal of human behaviour, 33, 26-29.

Wnuk, M., Marcinkowski, J. T., \& Fobair, P. (2012). The relationship of purpose in life and hope in shaping happiness among patients with cancer in Poland. Journal of Psychosocial Oncology, 30, 461-483. https://doi.org/10.1080/07347332.2012.684988 
Publisher's Note Springer Nature remains neutral with regard to jurisdictional claims in published maps and institutional affiliations. 